\title{
A Bipolar Output Active-Switched-Inductor Converter for Bipolar DC Microgrid
}

\author{
Yingjun Guo $\mathbb{D}$ and Hexu Sun (i) \\ School of Electrical Engineering, Hebei University of Science and Technology, Shijiazhuang 050018, China \\ Correspondence should be addressed to Hexu Sun; hxsun@hebust.edu.cn
}

Received 30 May 2021; Revised 16 November 2021; Accepted 14 December 2021; Published 19 January 2022

Academic Editor: Leonardo Sandrolini

Copyright (C) 2022 Yingjun Guo and Hexu Sun. This is an open access article distributed under the Creative Commons Attribution License, which permits unrestricted use, distribution, and reproduction in any medium, provided the original work is properly cited.

\begin{abstract}
A bipolar DC microgrid shows good performance since it improves the efficiency and system's reliability. To transmit power to the load, several DC-DC converters are required by the conventional bipolar DC microgrid, which results into large weight, volume, and high cost. To integrate bipolar DC microgrid with the photovoltaic (PV) module, a novel bipolar output converter is proposed in this paper. This converter possesses very simple circuit configuration and can achieve a high stepup voltage gain by adopting active-switched-inductor (ASL) network; meanwhile, bipolar output voltage is between positive line $(\mathrm{P})$, negative line $(\mathrm{N})$, and common ground $(\mathrm{O})$, which can offer three voltage classes $(\mathrm{Vdc},+0.5 \mathrm{Vdc}$ and $-0.5 \mathrm{Vdc}$ ). To verify the precision of the analysis of the proposed converter, a prototype has been designed and experiments are performed in the lab.
\end{abstract}

\section{Introduction}

As the global energy crisis and environmental pollution become more and more serious, distributed generations such as photovoltaic (PV) and wind power have attracted more and more attention because of its renewable, clean, and other advantages. However, distributed power generation has some disadvantages, such as randomness and intermittent fluctuations. Therefore, connecting new energy to the grid through the microgrid has become a future development trend [1-5]. The microgrid system includes DGs, energy storage units, distributed loads, and interface converters. There are two types of microgrids: DC microgrid and AC microgrid. Since grid exists in the form of communication, most of the current research on microgrid focuses on micro networks. The output of photovoltaic and energy storage units is in the form of DC, and a large number of loads also obtain electrical energy in the form of DC. In this case, the DC microgrid has the following advantages as compared with the AC microgrid [6-8]:
(1) There are fewer energy conversion stages, which means power losses are reduced and system efficiency is improved

(2) There are fewer power electronic devices; the costs get reduced

(3) The power outputs do not need to be synchronized; the control strategy is simple without considering such factors as frequency, phase angle, and reactive power

(4) The load power supply is not affected by the network voltage drop, sudden rise, phases imbalance, and harmonics wave, so the power quality is better

Therefore, DC microgrids are especially researched all over the world.

In the DC microgrid, renewable energy and energy generated by energy storage devices can be transmitted through a bipolar bus or a unipolar bus. DC microgrid can be divided into unipolar microgrid and bipolar microgrid. Compared 
with the unipolar DC microgrid, the bipolar DC microgrid has the following advantages [9-12]:

(1) When either bus gets failed, the other buses can work normally

(2) The current through ground is closed to zero, during the normal operation

(3) As compared to the unipolar DC microgrid, the current in the bipolar DC microgrid must be smaller, when the same power is transmitting in the bipolar DC microgrid

(4) Three voltage levels are introduced by the bipolar DC bus, comprising a negative voltage and two symmetrical positive voltage

Hence, high efficiency, flexibility, and reliability can be achieved by the bipolar DC microgrid system. The structure of the bipolar power grid is shown in Figure 1. According to its characteristics, many researches about bipolar output converters have been done [13-15]; Figure 1 illustrates the structure of bipolar DC microgrid, which helps to reduce energy conversion stages and increase microgrid system efficiency. The main problem of bipolar output converter is that different loads will cause bipolar output to be different; in order to solve this problem, some control strategies on voltage balancer have been proposed [16-18].

The voltage stress of the semiconductor devices and the power quality get affected by the unbalance voltage; therefore, it is essential to have symmetrical bipolar output voltage for the application of bipolar DC microgrid. In recent years, the research of voltage balancers is getting further due to the quick development of DC microgrid technologies. The voltage balancer can be used into two applications: isolated and nonisolated. The isolated voltage balancers of DAB are introduced in $[19,20]$. However, the isolated voltage balancers require more devices and magnetic components. For some situations where there is no need to provide isolation between the AC and DC grids, nonisolated voltage balancers are needed. Some voltage balancer of buck/boost type applied in bipolar DC bus is proposed in [21-23], and it has been successfully employed to DC microgrid. A voltage balancer employing dual-buck topologies is introduced in [24]. Some three-level (TL) converters with bipolar output are proposed in [25-27], which adopt balance control. In [18], a number of bipolar output converters, based on zeta converter, SEPIC converter, Cuk converter, and buck/boost converter, are introduced that could supply bipolar voltage to the loads. In [28], a bipolar output converter based on a combination of both SEPIC and Cuk converter is proposed, which has no balance control and inherently bipolar output; however, the complexity of converter and a number of components make the efficiency performance not well. Using independent neutral modules is another method to balance the positive and negative DC bus voltages for two-level or three-level converters. In [29], an independently controlled neutral module (ICNM) was used in three-phase four-wire inverter to provide the path for neutral current under unbalanced load condition, which can help balance the positive and negative voltages; however, the resonance will occur between the neutral inductor and the DC-link capacitors, so the neutral inductor current feedback scheme (ICFS) was proposed in [29] to improve the phase margin to ensure system stability. Also, to reduce the neutral point voltage ripple, three improved control schemes, namely, the neutral current feedforward plus inductor current feedback scheme (NFICFS), proportional resonant cascaded regulator plus inductor current feedback scheme (PR+ICFS), and neutral current feedforward plus inductor current feedback scheme (NCFF $+\mathrm{ICFS}$ ), were proposed in [29] to reduce the neutral point voltage ripple and balance the positive and negative DC bus voltages. In [30], power decoupling network (PDN) is embedded for reducing the split DC bus capacitance. To restrain the PDN from producing excessive power losses, partial power processing is proposed, such that the PDN and the split DC bus capacitors share the midpoint current and the neutral current per an optimal current distribution factor.

Based on the structure and characteristics of bipolar DC microgrid, this paper suggests a bipolar output DC-DC converter based on ASL; the ASL network has a simple topological structure, the operation mode of the two parallel charging series inductance discharge with high voltage gain, components of current and voltage stress are relatively low; in addition, owning to inherent structure of the suggested converter, balance control is not required. The external characteristics and under various working modes the operation analysis of the converter have been discussed in detail. Finally, to verify the precision of the analysis, a prototype has been designed in the lab and results of experiments and simulations are given.

\section{Theory of Operation}

Figure 2 shows the proposed converter with ASL network. The ASL is made up of two inductors and two switches. When the switches are turned on simultaneously, the two inductors are charging in parallel; when the switches are turned off, the inductors are discharging in series, which helps to increase the voltage ratio. The voltage of $S_{2}$ was clamped by $C_{\mathrm{o} 1}, C_{\mathrm{i} 2}$, and the voltage of $S_{1}$ was clamped by $C_{\mathrm{o} 2}, C_{\mathrm{i} 1}$. And due to the symmetry of the structure, the converter can achieve voltage balance of bipolar output inherently without balance control. In order to analyze the discontinuous conduction mode (DCM) and continuous conduction mode (CCM) of the proposed converter, few assumptions are made.

(1) Ideal components are used in the circuit, and impact of ESR of capacitance and inductance, forward voltage drops across diodes, and switch's ON state resistance are ignored

(2) Identical input capacitors, output capacitors, and the inductors are chosen and possess the same values; therefore, 


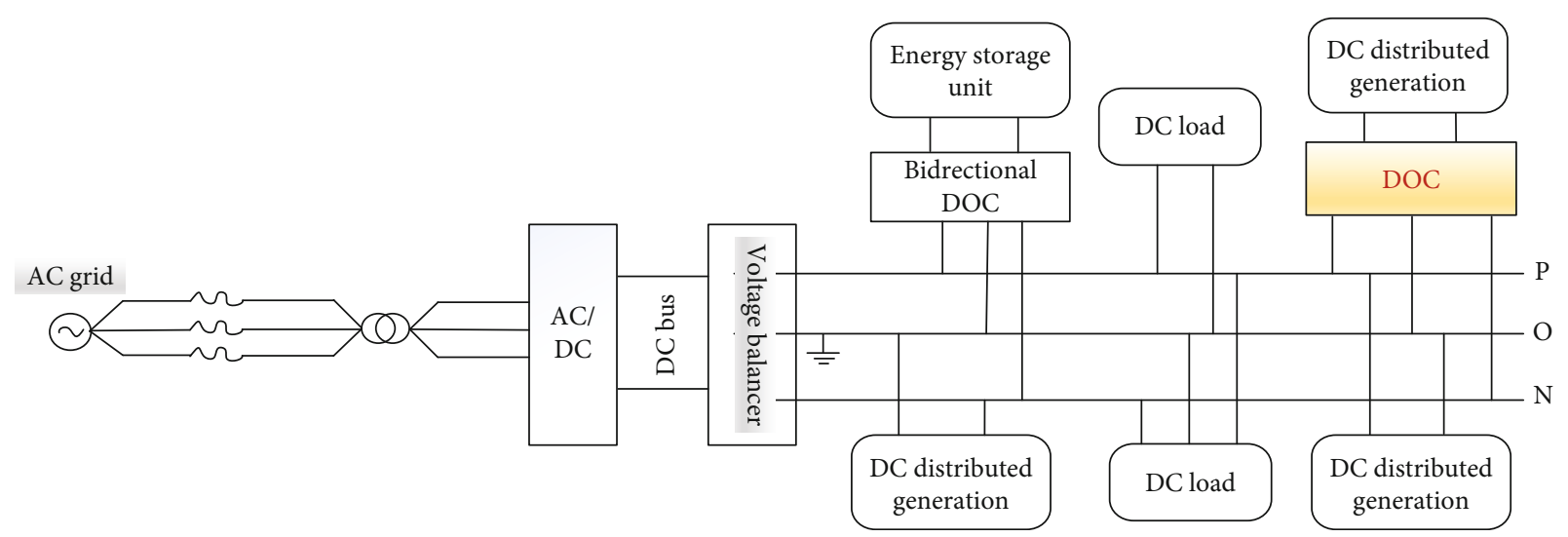

FIGURE 1: Structure of the bipolar DC microgrid.

$$
L_{1}=L_{2}=L, C_{\mathrm{i} 1}=C_{\mathrm{i} 2}, C_{\mathrm{o} 1}=C_{\mathrm{o} 2} \text {. }
$$

(3) The DC loads between PO and NO are symmetrical due to the control of the voltage balancer in DC microgrid, which is the most important for operation of the proposed converter

(4) Assuming the converter and DC microgrid operates in the steady state

2.1. Analysis of CCM Operation. During the CCM, Figure 3 describes the typical characteristics of the proposed converter, with respect to the equivalent circuits and key waveforms illustrated in Figures 3 and 4; the CCM operation mode is analyzed as follows.

(1) Mode $1\left[t_{0}, t_{1}\right]$ : the proposed converter equivalent power circuit in mode 1 is illustrated in Figure 4(a) in which switches $S_{1}$ and $S_{2}$ are turned ON. In this mode, the inductors are charging in parallel by the input voltage $V_{\mathrm{i}}$, and the current through inductors increases linearly; the voltage across the inductors can be expressed as

$$
L_{1} \frac{d i_{L 1}}{d t}=L_{2} \frac{d i_{L 2}}{d t}=V_{L_{1}}=V_{L_{2}}=V_{\mathrm{i}}
$$

(2) Mode $2\left[t_{1}, t_{2}\right]$ : the proposed converter equivalent power circuit in mode 2 is illustrated in Figure 4(b) in which switches $S_{1}$ and $S_{2}$ are turned OFF. During this mode, both inductors are discharging in series and the two loads are absorbing power from each of the inductors. The voltage across the inductors is

$$
\left\{\begin{array}{l}
V_{L 1}=V_{C \mathrm{i} 1}-V_{C o 1} \\
V_{L 2}=V_{C \mathrm{i} 2}-V_{C \mathrm{o} 2}
\end{array}\right.
$$

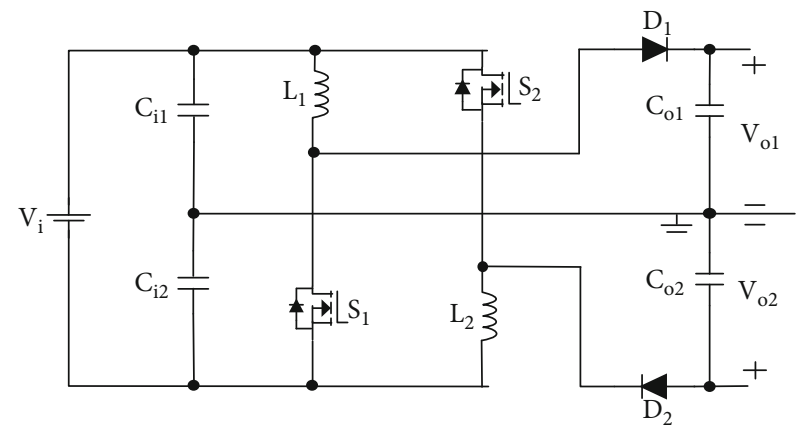

Figure 2: The proposed converter.

2.2. Analysis of DCM Operation. The discontinuous conduction mode of the proposed converter is classified into three modes. For discontinuous conduction mode, typical characteristics of the proposed converter are shown in Figure 5. Mode 1 and mode 2 are similar as continuous conduction mode; in inductors, no current is flowing after $t_{D}$ is the main difference as shown in Figure 6; in this mode, the loads are only getting charged by $V_{\mathrm{CO} 1}$ and $V_{\mathrm{CO} 2}$. It can be observed that from time $t_{D}$ to $T_{s}$ the current of the inductors is zero.

\section{Circuit Performance Analysis}

Due to the circuit symmetry of the proposed converter, the performance analysis of the circuit is illustrated as follows.

3.1. Voltage Conversion. In order to simplify the analysis, assumptions are as follows: output voltage and input voltage are constant and capacitors $C_{\mathrm{i} 1}, C_{\mathrm{i} 2}, C_{\mathrm{o} 1}$, and $C_{\mathrm{o} 2}$ are large enough, so $V_{\mathrm{Ci} 1}=V_{\mathrm{i}} / 2=V_{\mathrm{Ci} 2}, V_{\mathrm{Co} 1}=V_{\mathrm{o}} / 2=V_{\mathrm{Co} 2}$.

By using voltage-second balance on inductors $L_{1}, L_{2}$,

$$
\begin{gathered}
D \cdot V_{\mathrm{i}}+(1-D) \cdot\left(V_{\mathrm{Ci} 2}-V_{\mathrm{Co} 2}\right)=0, \\
D \cdot V_{\mathrm{i}}+(1-D) \cdot\left(V_{\mathrm{Ci} 2}-V_{\mathrm{Co} 2}\right)=0 .
\end{gathered}
$$

Simplifying (4) and (5), the voltage gain of the CCM operation is 


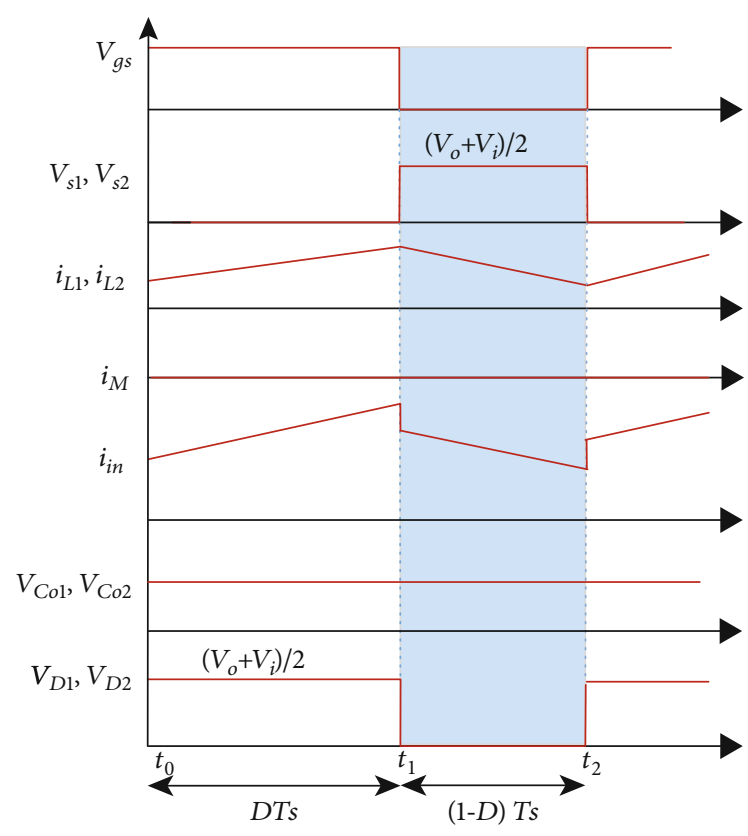

FIgURE 3: Key waveform in CCM operation.

$$
G_{\mathrm{CCM}}=\frac{V_{\mathrm{o}}}{V_{\mathrm{i}}}=\frac{D+1}{1-D} .
$$

3.2. DCM Voltage Conversion Ratio. Under DCM operation, the inductor's current increases, when the switches are conducting and its peak current is

$$
i_{L 1 p}=i_{L 2 p}=\frac{V_{i} D T_{s}}{L}
$$

The inductor's current decreases, when the switches are off, and its peak current is

$$
i_{L 1 p}=i_{L 2 p}=\frac{\left(V_{\mathrm{o}}-V_{\mathrm{i}}\right) D_{2} T_{s}}{2 L}
$$

where $D_{2} T_{s}$ is the duration time of mode 2 .

$D_{2}$ can be derived from (8) and (7) as follows:

$$
D_{2}=\frac{2 V_{\mathrm{i}}}{V_{\mathrm{o}}-V_{\mathrm{i}}} D
$$

The average current of output capacitor in a period is zero, so

$$
I_{\mathrm{o}}=\frac{i_{L 1 p} D_{2}}{2}=\frac{V_{\mathrm{o}}}{R_{L}} .
$$

Substituting (9) into (10), $G_{\mathrm{DCM}}$ is derived as

$$
G_{\mathrm{DCM}}=\frac{1}{2}+\sqrt{\frac{1}{4}+\frac{D^{2}}{\tau}},
$$

where $\tau$ is a time constant which can be defined as $\tau=$ $L f_{s} / R L$.

The voltage gain of the CCM is equal to that of the DCM when the converter is operating in critical continuous state; according to (6) and (11), intrinsic time $\tau$ can be derived as

$$
\tau^{\prime}=\frac{D(1-D)^{2}}{2(1+D)}
$$

According to (8) and (9), in the condition of critical continuous state, the current of loads is

$$
I_{\mathrm{o}}^{\prime}=\frac{\Delta I_{L}}{2}(1-D)=\frac{V_{\mathrm{o}} T_{s} D(1-D)^{2}}{2 L(1+D)} .
$$

When $D=0.281$, the current of loads reaches the maximum

$$
I_{\mathrm{o} \max }^{\prime}=0.0567 \frac{V_{\mathrm{o}}}{L f_{s}} .
$$

So, the current of loads can be represented as

$$
I_{\mathrm{o}}^{\prime}=\frac{I_{\mathrm{o} \max }^{\prime} D(1-D)^{2}}{0.0567(1+D)} .
$$

According to (6), (10), and (15), Figure 7 shows the relationship between duty cycle, current of loads, and gain.

3.3. Efficiency Analysis considering Nonideality under CCM. Figure 8 illustrates the equivalent circuit of the proposed converter with nonidealities. It is considered that the inductors are alike and $r_{L}$ is their effective series resistance $\left(L_{1}=L_{2}=L\right.$ and $\left.r_{L 1}=r_{L 2}=r_{L}\right)$. Also, it is considered that all the diodes $D$ are alike and possess forward voltage drop $V_{\mathrm{FD}}\left(V_{\mathrm{FD} 1}=V_{\mathrm{FD} 2}\right)$ and forward resistance $r_{D}\left(r_{D 1}=r_{D 2}\right)$. The two switches are also alike and possess $\mathrm{ON}$ state resistance $r_{S}\left(r_{S 1}=r_{S 2}\right)$.

In mode $\mathrm{I}$, the average voltage across the inductors and the average current through the output capacitor are derived as

$$
\left\{\begin{array}{l}
I_{C 1}=-\frac{V_{o 1}}{R_{o 1}}=-\frac{V_{o}}{2 R_{o 1}}, \\
I_{C 2}=-\frac{V_{o 2}}{R_{o 2}}=-\frac{V_{o}}{2 R_{o 1}}, \\
V_{L 1}=V_{L 2}=V_{\text {in }}-i_{L}\left(r_{L}+r_{S}\right) .
\end{array}\right.
$$

In mode II, average voltage across the inductors and the average current through the output capacitors are derived as 


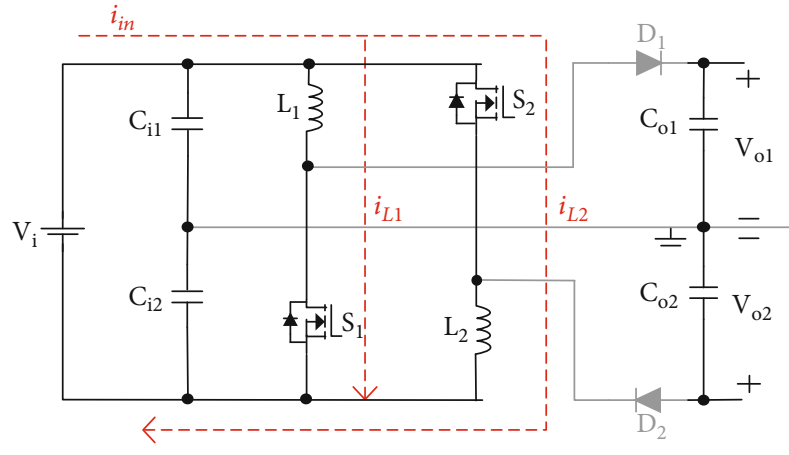

(a)

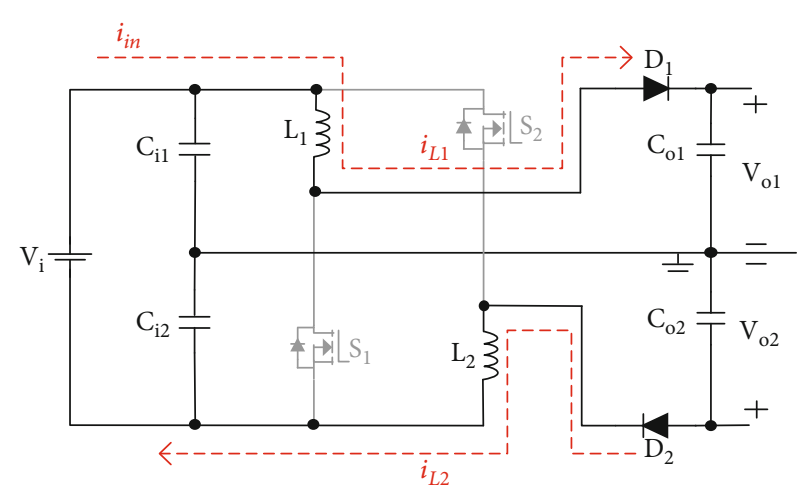

(b)

FIgURE 4: The equivalent circuit in CCM operation: (a) mode 1 and (b) mode 2.

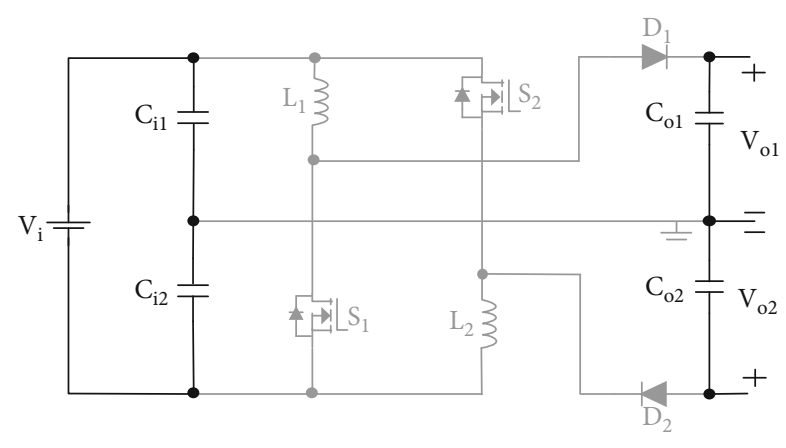

FIGURE 5: Mode 3 in DCM operation.

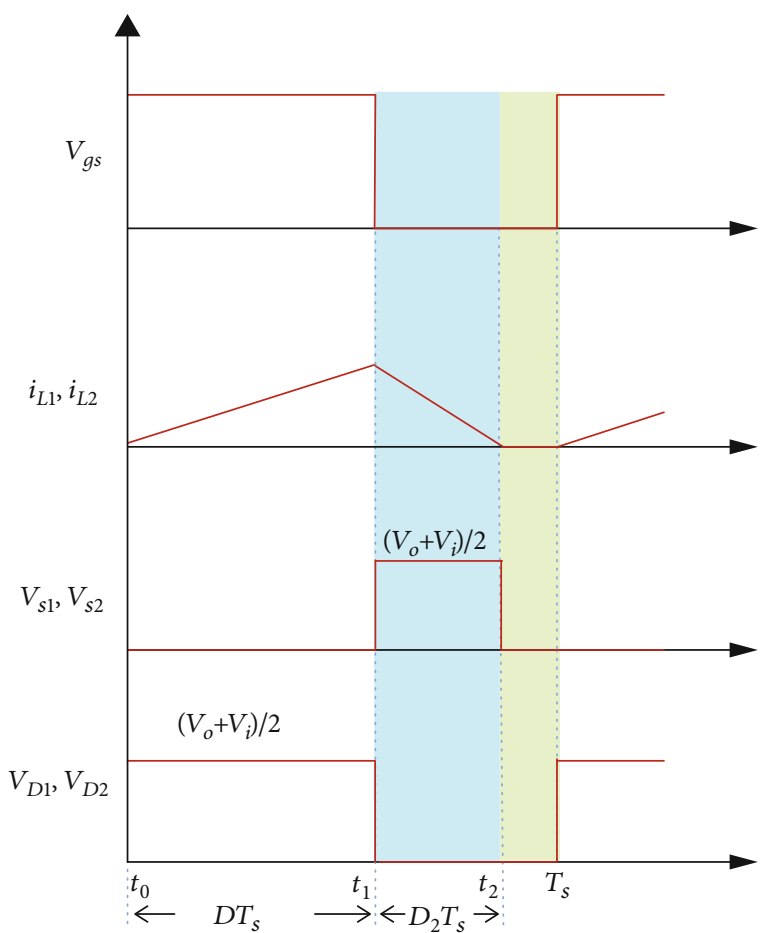

FIgURE 6: Key waveform in the DCM.

$$
\left\{\begin{array}{l}
I_{C 1}=-\frac{V_{o 1}}{R_{o 1}}=-\frac{V_{o}}{2 R_{o 1}} \\
I_{C 2}=-\frac{V_{o 2}}{R_{o 2}}=-\frac{V_{o}}{2 R_{o 2}} \\
V_{L 1}=V_{L 2}=\frac{1}{2}\left[V_{\text {in }}-i_{L}\left(2 r_{L}+2 r_{D}\right)-V_{o}-2 V_{F D}\right]
\end{array}\right.
$$

The voltage gain of the converter

$$
G_{\text {real }}=\frac{1+D-A}{1-D+B}=\frac{G_{\text {ideal }}-(A /(1-D))}{1+(B /(1-D))},
$$

Where $A=2(1-D) V_{\mathrm{FD}}$ and $B=2\left[r_{L}+D r_{S}+(1-D) r_{D}\right]$ $/ R_{o 1}$.

The proposed converter's power loss and efficiency can be derived as

$$
\eta^{\prime}=\frac{1-D^{2}-2(1-D)^{2} V_{\mathrm{FD}}}{1-D^{2}+\left(\left(\left[r_{L}+D r_{S}+(1-D) r_{D}\right](1+D)\right) / R_{o 1}\right)}
$$

3.4. Voltage and Current Stress of the Power Devices. The diode and power switch current and voltage stresses with respect to the analysis of CCM operation modes are

$$
\begin{gathered}
V_{D 1}=V_{D 2}=V_{S 1}=V_{S 2}=\frac{1}{1+D} V_{o}, \\
\left\{\begin{array}{l}
I_{S 1}=I_{S 2}=I_{L}+\Delta I_{L}=I_{o}+\frac{D(1-D) V_{o}}{(D+1) 2 f_{s} L} \\
I_{D 1}=I_{D 2}=\Delta I_{L}+I_{L}=I_{o}+\frac{D(1-D) V_{o}}{(D+1) 2 f_{s} L} .
\end{array}\right.
\end{gathered}
$$

As shown in Figure 9, the voltage stress of all power devices is lower than output voltage, which greatly reduces the power loss of switches and solves the reverse recovery problem of diodes; the current stress of power devices is also reduced due to the ASL unit. In addition, thanks to the 


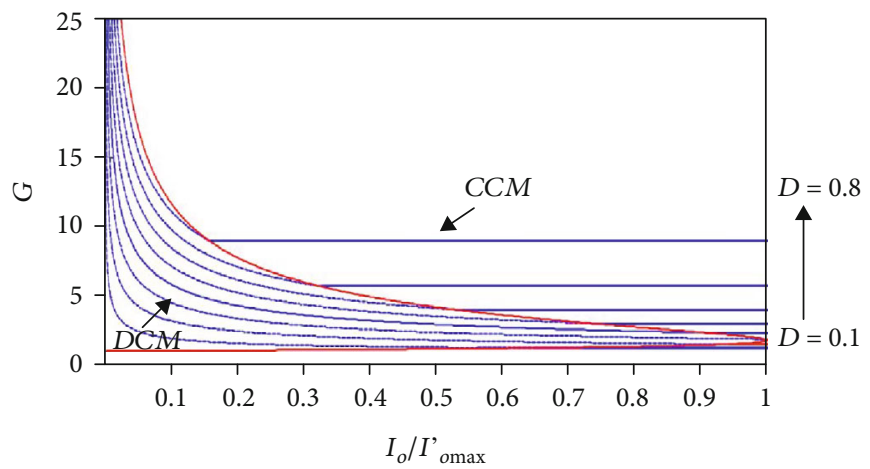

Figure 7: The relationship between duty cycle, current of loads, and gain.

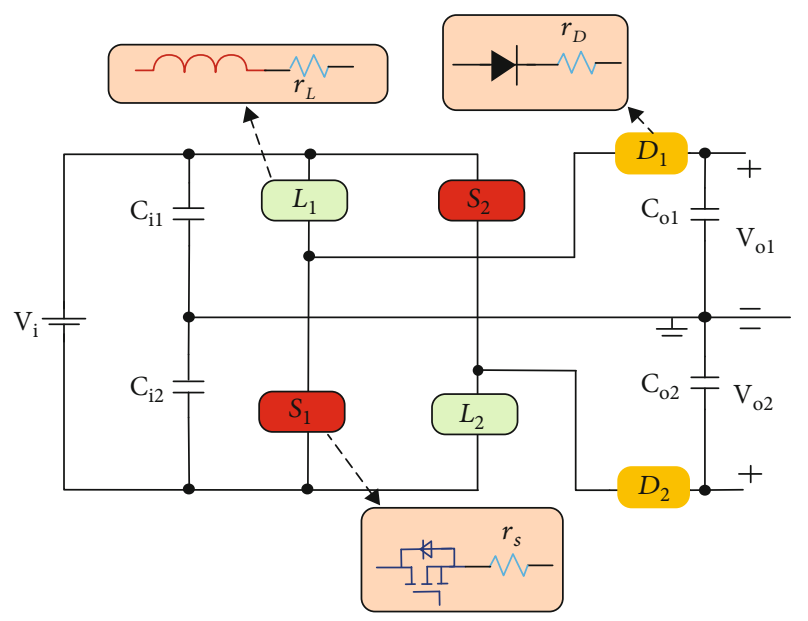

Figure 8: The equivalent circuit of the proposed converter with nonidealities.

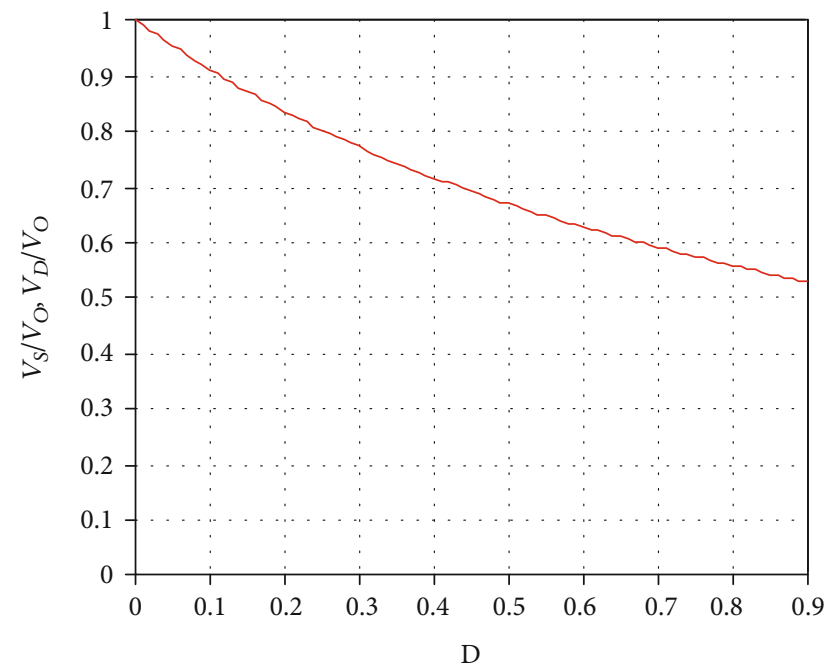

FIGURE 9: The relationships between voltage stress on switches and diodes with duty cycle. clamping structure of four capacitors, not only the circuit resonance problem is well solved when the switch is turned off but also the voltage on two switches and diodes can keep balance.

3.5. The Analysis of Input Current and Output Voltage Ripple. According to the current waveform in Figure 3, the current through inductors and neutral line can be derived as

$$
i_{L 1}=i_{L 2}=\left\{\begin{array}{l}
I_{L}\left(t_{0}\right)+\frac{V_{i}}{L}\left(t-t_{0}\right), \quad t_{0} \leq t<t_{1}, \\
I_{L}\left(t_{1}\right)+\frac{V_{i}-V_{o}}{2 L}\left(t-t_{2}\right), \quad t_{1} \leq t<t_{2}, \\
i_{M}=0 .
\end{array}\right.
$$

So, the input current can de expressed as

$$
\begin{aligned}
& i_{\text {in }}=\left\{\begin{array}{l}
\frac{2 V_{o}}{R(1-D)}-\frac{D(1-D) V_{o}}{f_{s} L(1+D)}+\frac{(1-D) 2 V_{o}}{L(1+D)}\left(t-t_{0}\right), \quad t_{0} \leq t<t_{1}, \\
\frac{V_{o}}{R(1-D)}+\frac{V_{o}(1-D) D}{2 f_{s} L(1+D)}+\frac{D V_{o}}{L(1+D)}\left(t-t_{2}\right), \quad t_{1} \leq t<t_{2},
\end{array}\right. \\
& \Delta i_{\text {in }}=\frac{V_{o}}{(1-D) R_{o}}+\frac{3 D(1-D) V_{o}}{2 f_{s} L(D+1)} .
\end{aligned}
$$

The current effective value of the switches is

$$
\begin{aligned}
I_{\text {rms-s }} & =\sqrt{\frac{1}{T} \int_{0}^{D T}\left(I_{L}-\frac{1}{2} \Delta I_{L}+\frac{\Delta I_{L}}{D T} t\right)^{2}} \\
& =I_{o} \sqrt{\frac{(G+1)(G-1)}{2}} \sqrt{\frac{1}{12} K_{i}^{2}+1}
\end{aligned}
$$

where $K_{i}=\triangle I_{L} / i_{L}$. 


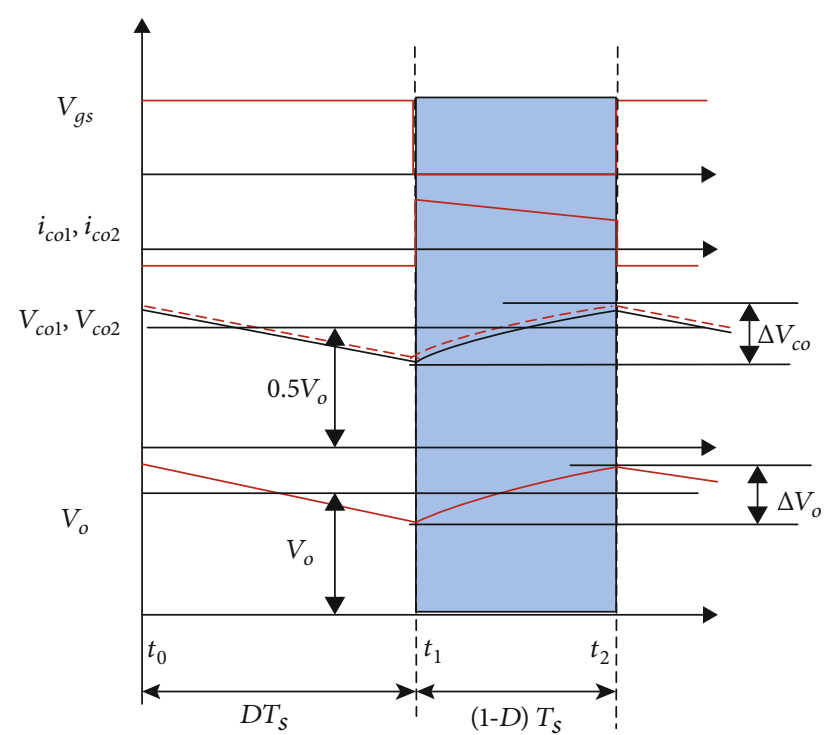

Figure 10: The waveforms of output.

The ripple of output capacitor voltage with respect to Figure 10 can be derived as

$$
\begin{aligned}
& \Delta V_{o 1}(t)=\Delta V_{o 2}(t)=\left\{\begin{array}{l}
\frac{1}{C_{1}} \int_{t_{0}}^{t} I_{o} d t, \quad t_{0}<t<t_{1}, \\
\frac{1}{C_{1}} \int_{t 1}^{t} i_{L 1}(t)-I_{o} d t, \quad t_{1}<t<t_{2},
\end{array}\right. \\
& \Delta V_{o}=\Delta V_{o 1}+\Delta V_{o 2}=\frac{V_{o} D}{R_{o} f_{s} C_{o}} .
\end{aligned}
$$

\section{Design of Parameters}

In order to verify the analysis, we have established a prototype in laboratory; the following is the main design criterion.

4.1. Inductor Design. The same equation can be used to calculate the current ripple of the inductors $L_{1}$ and $L_{2}$. The inductor's section depends on duty cycle $(D)$, inductor ripple current $\left(\triangle i_{L}\right)$, inductor voltage $\left(V_{L}\right)$, and switching frequency $\left(f_{\mathrm{s}}\right) . V_{\mathrm{i}}$ is equal to the voltage of the input inductance $L_{1}$ and $L_{2}$. Hence, the inductance value of $L_{1}$ and $L_{2}$ can be expressed as

$$
L_{1}=L_{2} \geq \frac{V_{i} D T_{s}}{K_{i} i_{L}} .
$$

4.2. Capacitor Design. The value of the output capacitors $C_{\mathrm{ol}}$ and $C_{\mathrm{o} 2}$ depends on the switching frequency $f_{\mathrm{s}}$, output voltage $V_{\mathrm{o}}$, converter's output power $P_{0}$, and voltage ripple $\triangle V_{\mathrm{o}}$. The rating of the capacitor $C$ can be obtained as follows:
TABLE 1: Experimental conditions.

\begin{tabular}{lc}
\hline Components & Parameters \\
\hline$V_{\mathrm{i}}$ (input voltage) & $60-80 \mathrm{~V}$ \\
$V_{\mathrm{o}}$ (output voltage) & $\pm 120 \mathrm{~V}$ \\
$P_{\mathrm{o}}$ (rated power) & $200 \mathrm{~W}$ \\
$f_{\mathrm{s}}$ (switching frequency) & $50 \mathrm{kHz}$ \\
\hline
\end{tabular}

TABLE 2: Experimental conditions.

\begin{tabular}{lc}
\hline Components & Parameters \\
\hline$S_{1}, S_{2}$ (switches) & IRFP250 \\
$D_{1}, D_{2}$ (diodes) & $\mathrm{SF} 24$ \\
$L_{1}, L_{2}$ (inductors) & $240 \mu \mathrm{H}$ \\
$C_{\mathrm{i} 1}, C_{\mathrm{i} 2}$ (input capacitors) & $1000 \mu \mathrm{F} / 100 \mathrm{~V}$ \\
$C_{\mathrm{o} 1}, C_{\mathrm{o} 2}$ (output capacitors) & $470 \mu \mathrm{F} / 250 \mathrm{~V}$ \\
\hline
\end{tabular}

$$
C_{\mathrm{o} 1}=C_{\mathrm{o} 2} \geq \frac{2(1-D) T_{s} I_{o}}{K_{V} V_{\mathrm{o}}},
$$

where $K_{V}=\triangle V_{\mathrm{o}} / V_{\mathrm{o}}$.

4.3. Power Device Design. According to the working condition and formulas abovementioned, the maximum of voltage stress of all power devices is $160 \mathrm{~V}$, the theory current stress of switches is $2 \mathrm{~A}$, and the theory current stress of diodes is $0.8 \mathrm{~A}$. So, following these data and considering margin setting, the specific device selection can be easily found.

4.4. Controller Design Consideration. In DC microgrid, the second stage of the step-up DC-DC converter is usually a single-phase inverter load; the second harmonic current (SHC) will occur in the DC-DC converter when the instantaneous input and output power of two-stage single-phase converter is imbalanced. The SHC will propagate back into the front-end DC-DC converter and the input DC voltage source. For the front-end DC-DC converter, the SHC will lead to higher current stress for power switches and produce extra power losses in power switches and magnetic components. For the input DC voltage sources, such as batteries or fuel cells, the SHC will shorten the lifetime. To reduce the SHC, in $[31,32]$, a virtual-impedance approach is proposed; the virtual series impedance is realized by the feedback of the boost-diode current or the boost-inductor current, while the virtual parallel impedance is implemented by the feedback of the DC bus voltage. Based on the approach, the SHC reduction control schemes are proposed. The proposed converter is similar to the prestage boost converter in $[31,32]$, so the controller design of the proposed converter can refer to the closed-loop control scheme in these two papers.

\section{Simulation and Experiment Result}

To validate the accuracy of the theoretical analysis, the proposed converter prototype is designed and experiments are performed in the lab, and experimental conditions are given 


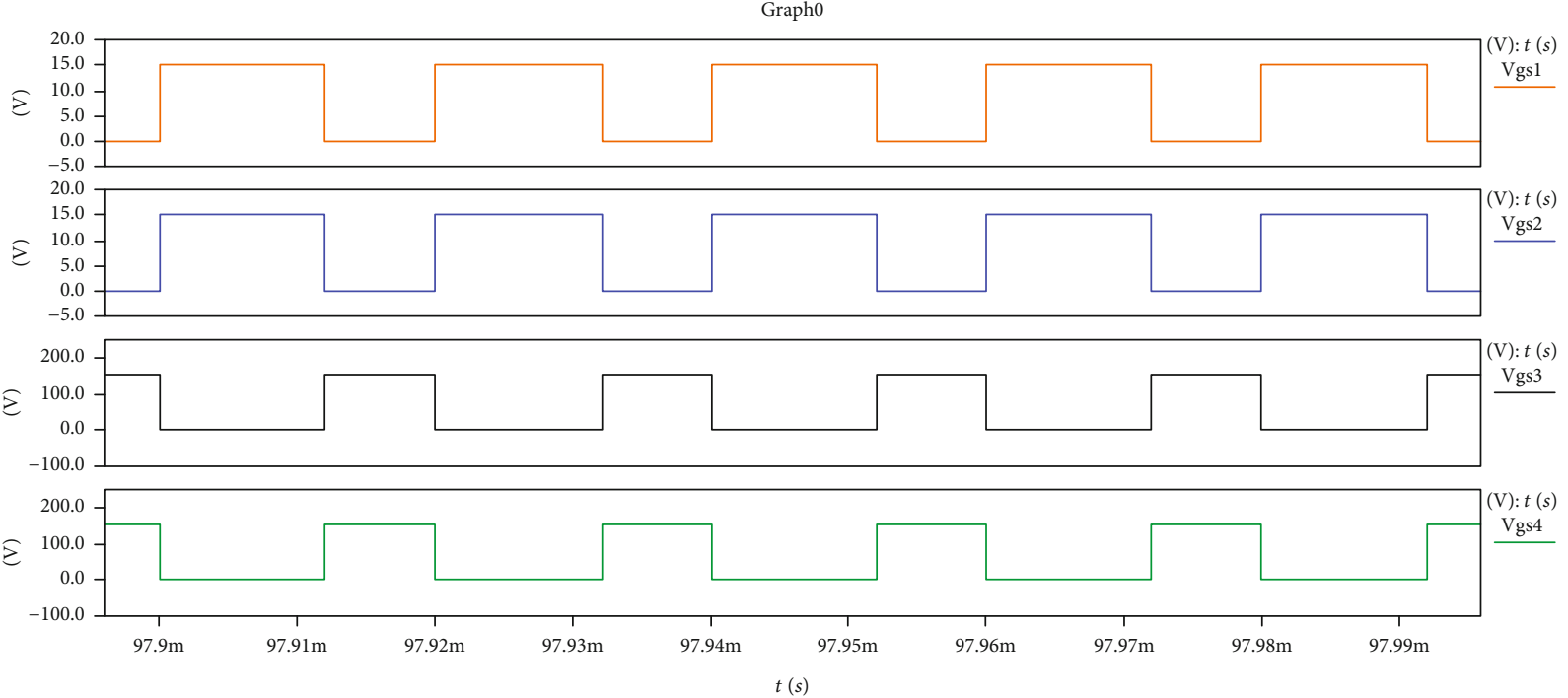

(a)

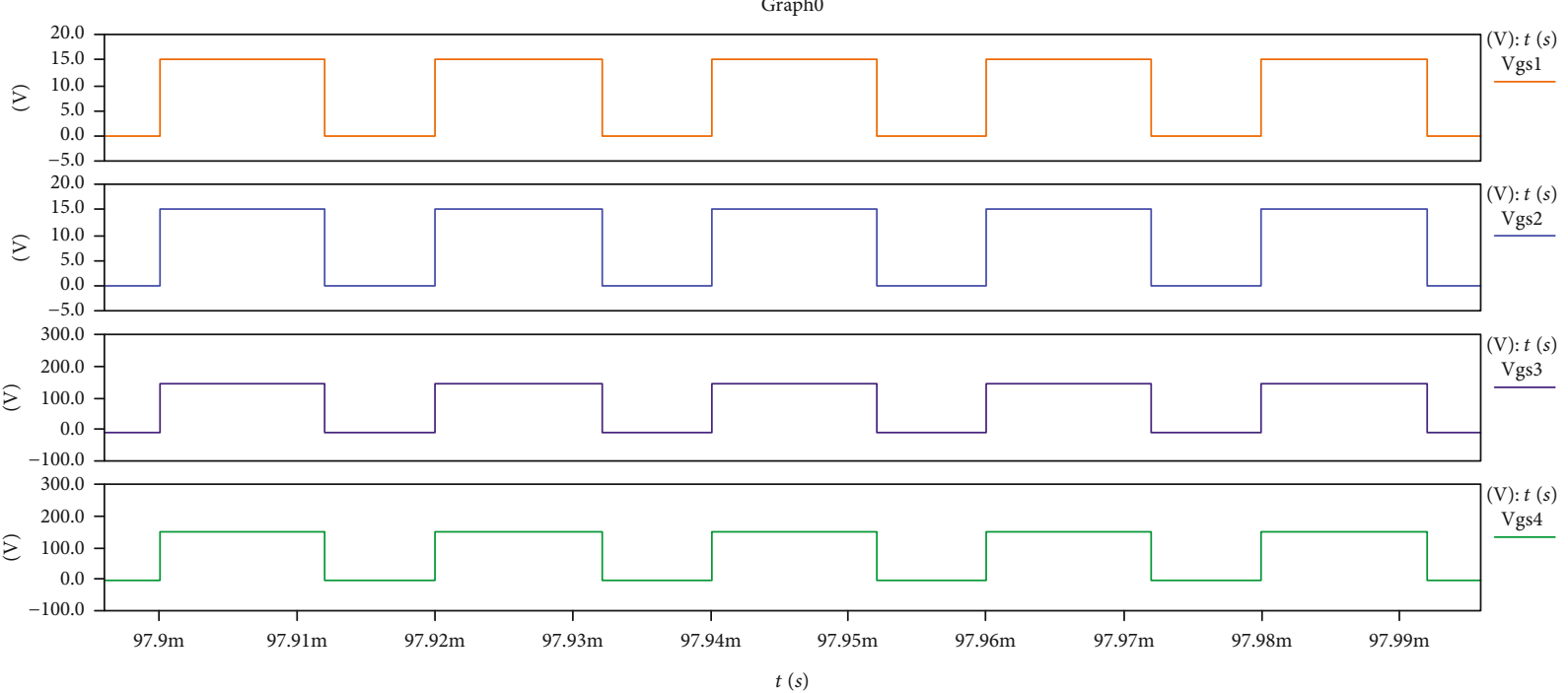

(b)

Figure 11: Continued. 


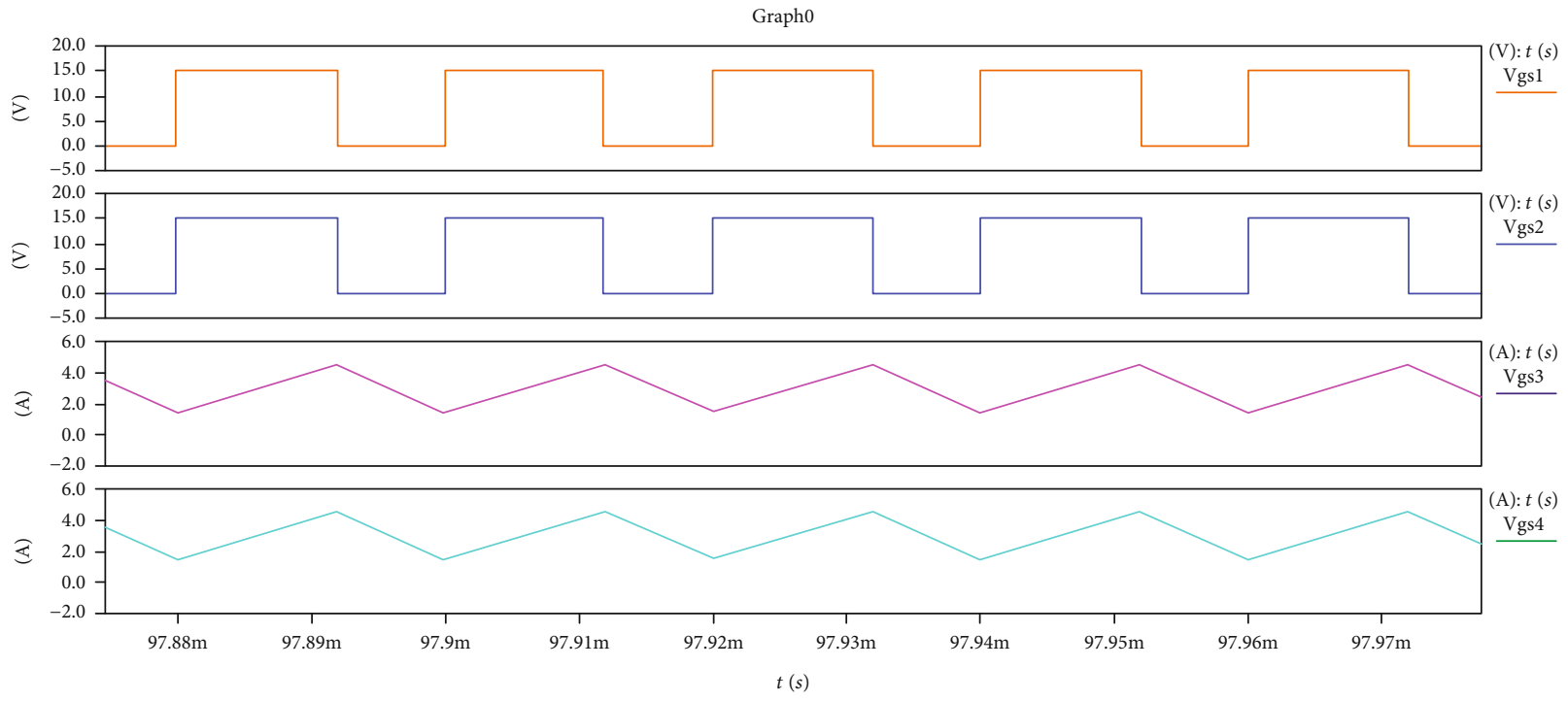

(c)

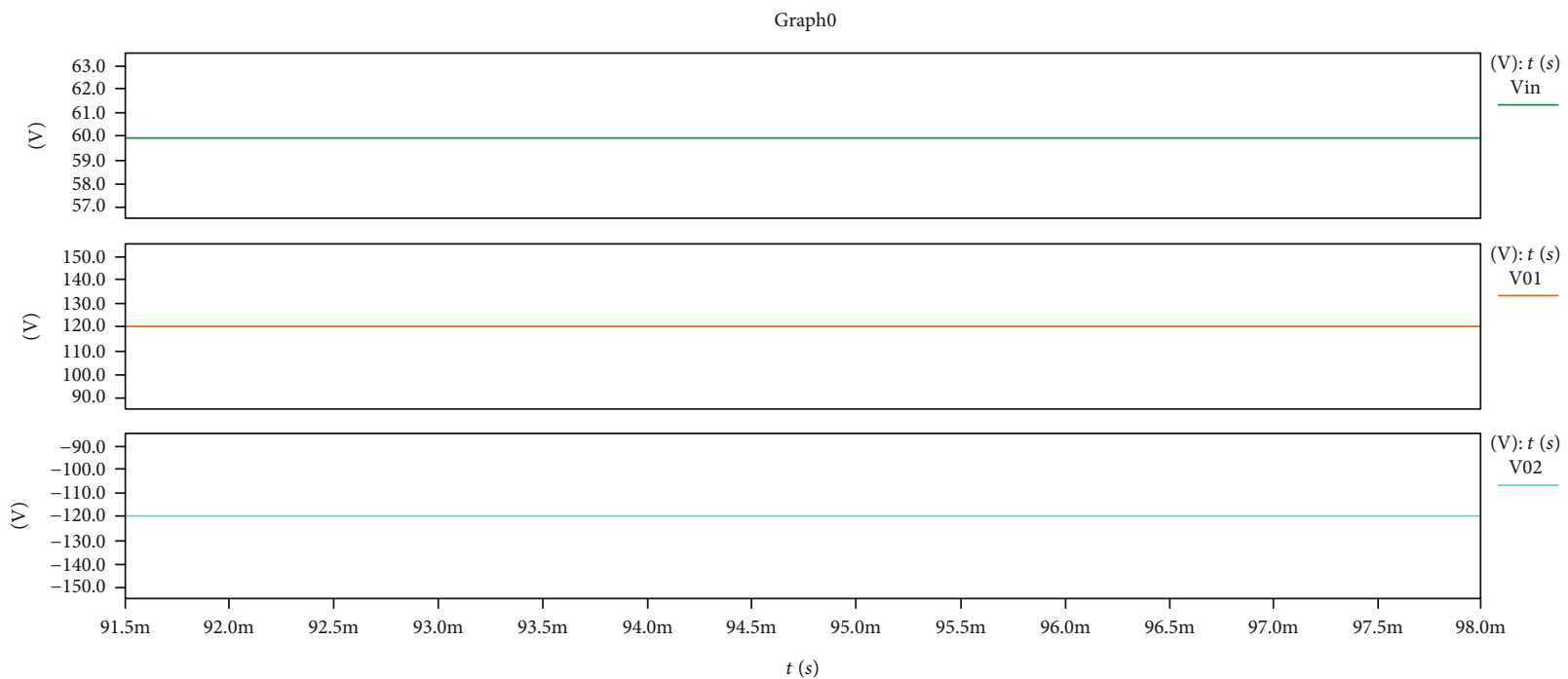

(d)

FIGURE 11: Simulation waveforms. (a) $V_{\mathrm{gs} 1}, V_{\mathrm{gs} 2}, V_{\mathrm{ds} 1}, V_{\mathrm{ds} 2} ;$ (b) $V_{\mathrm{gs} 1}, V_{\mathrm{gs} 2}, V_{\mathrm{D} 1}, V_{\mathrm{D} 2} ;$ (c) $V_{\mathrm{gs} 1}, V_{\mathrm{gs} 2}, i_{\mathrm{L} 1}, i_{\mathrm{L} 2} ;$ (d) $V_{\mathrm{in}}, V_{\mathrm{o} 1}, V_{\mathrm{o} 2}$.

in Table 1. According to the last section, the components and parameters are summarized in Table 2.

5.1. Simulation and Experimental Results. In the ideal condition, the simulation of the proposed converter is designed on Saber. As shown in Figures 11 and 12, the simulation and experimental results of the proposed converter are given to check analysis; it is obvious that experimental results are consistent with simulation results.

The converter is tested for output power $200 \mathrm{~W}$ (load $R$ $=290 \Omega$ ), input voltage $60 \mathrm{~V}$, and duty cycles $D=60 \%$. The voltage waveforms of switches $S_{1}, S_{2}$ are shown in Figures 11(a) and 12(a), the voltage stress $V_{\mathrm{S} 1}, V_{\mathrm{S} 2}$ is equal to theoretical half of the sum of input voltage and output voltage when the inductors are discharging, which benefit from the voltage-clamping topology of all capacitors. As shown in Figures 11(b) and 12(b), similar to switches, the voltage stresses of output diodes are also clamped by capacitors when switches are on and the voltage stress is the same as that of switches. Figures 11(c) and 12(c) show the inductor's current waveforms; the current is increasing linearly when switches are on and decreasing linearly when switches are off, which are consistent with the theoretical analysis. As for bipolar output converter designed for bipolar DC microgrid, the typical character is shown in Figures 11(d) and 12(d); thanks to the inherent symmetric structure, the voltage on two loads is the same and bipolar, which means $V_{\mathrm{o} 1}=+120 \mathrm{~V}$ and $V_{\mathrm{o} 2}=-120 \mathrm{~V}$ over the ground. Figure 13 shows sudden load change experiment of the proposed converter. According to Table 2, the rated power of the proposed converter is $200 \mathrm{~W}$. The sudden load increase experiment is shown in Figure 13(a), which is from $200 \mathrm{~W}$ to $100 \mathrm{~W}$. Sudden load decrease experiment is shown in Figure 13(b), which is from $100 \mathrm{~W}$ to 


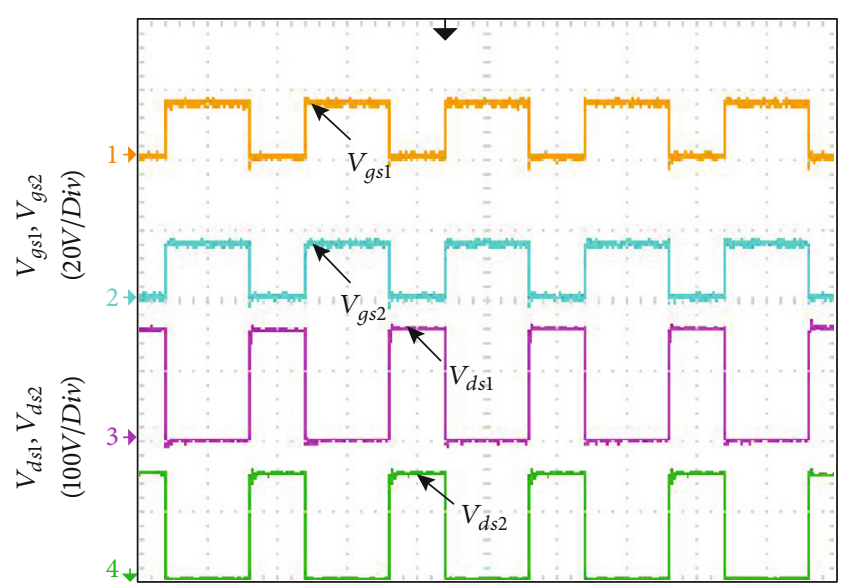

(a)

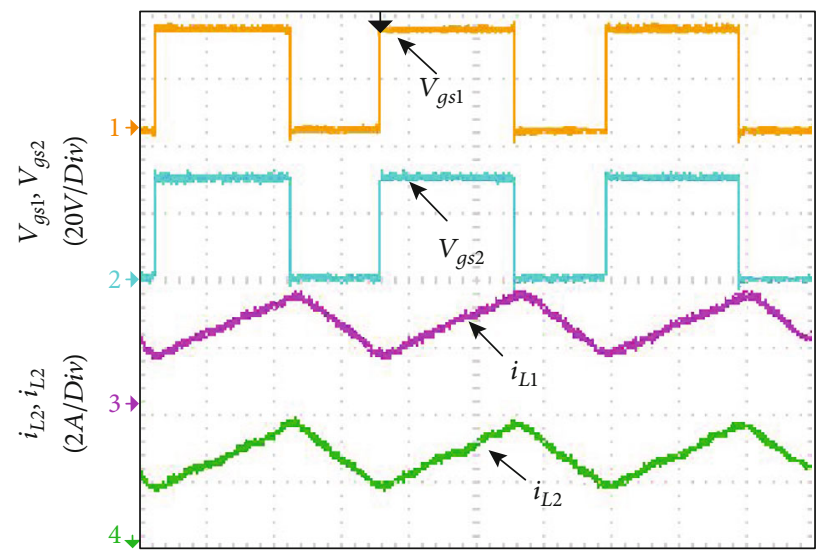

(c)

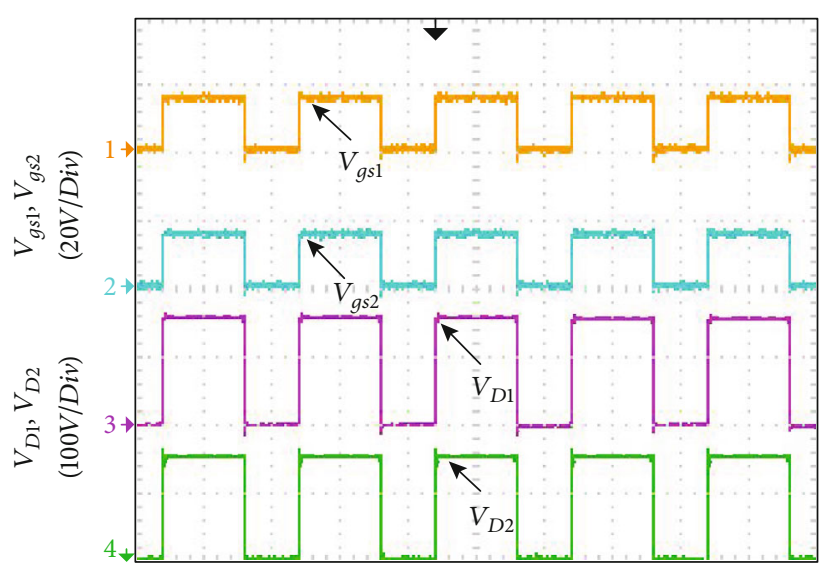

(b)

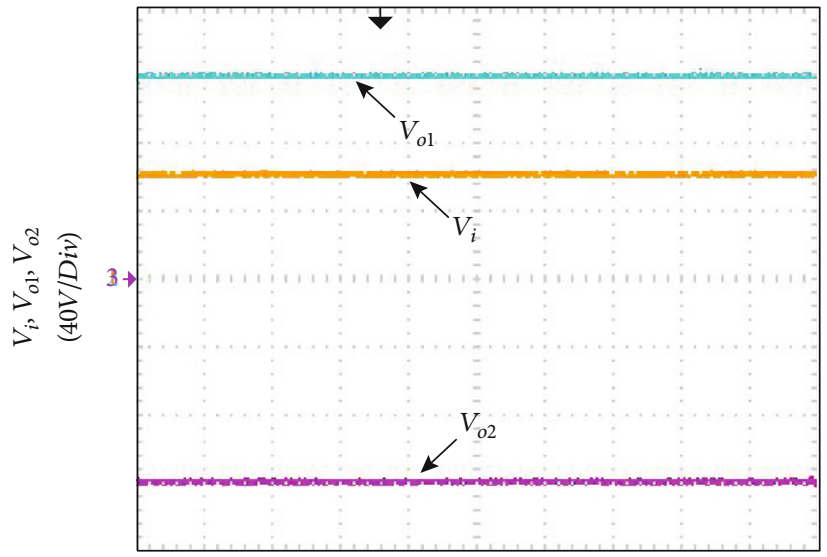

(d)

FIGURE 12: Experiment waveforms. (a) $V_{\mathrm{gs} 1}, V_{\mathrm{gs} 2}, V_{\mathrm{ds} 1}, V_{\mathrm{ds} 2} ;$ (b) $V_{\mathrm{gs} 1}, V_{\mathrm{gs} 2}, V_{\mathrm{D} 1}, V_{\mathrm{D} 2} ;$ (c) $V_{\mathrm{gs} 1}, V_{\mathrm{gs} 2}, i_{\mathrm{L} 1}, i_{\mathrm{L} 2} ;$ (d) $V_{\mathrm{in}}, V_{\mathrm{o} 1}, V_{\mathrm{o} 2}$.

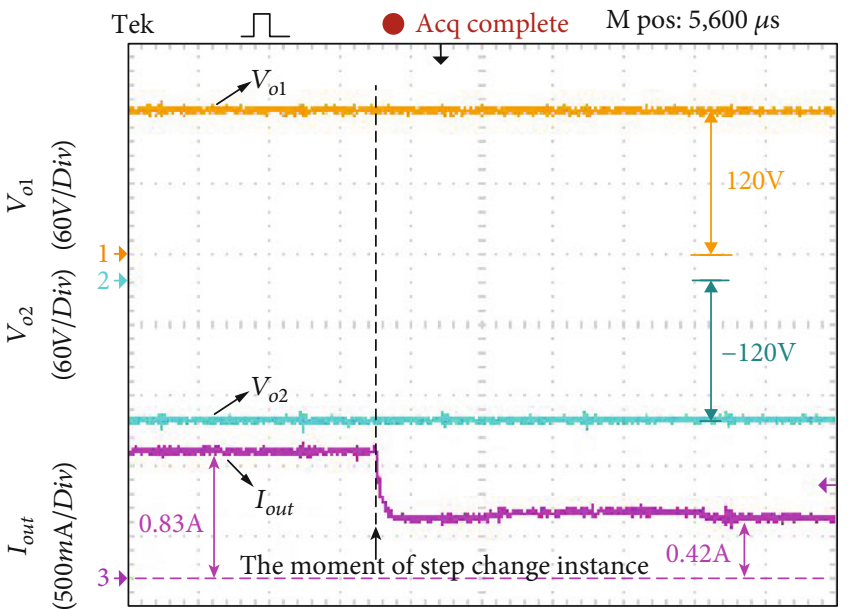

(a)

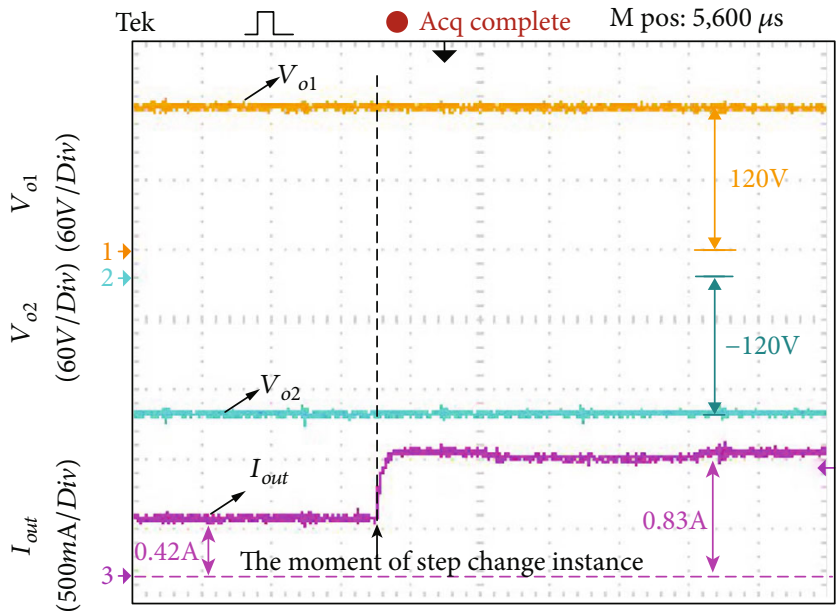

(b)

Figure 13: Sudden load change experiments: (a) sudden load increase and (b) sudden load decrease.

$200 \mathrm{~W}$. As shown in Figure 13(a), the output current decreases from $0.83 \mathrm{~A}$ to $0.42 \mathrm{~A}$ in a stepwise manner, and the proposed converter can balance the bipolar output voltages under a sudden load increase. As shown in
Figure 13(b), the output current increases from $0.42 \mathrm{~A}$ to $0.83 \mathrm{~A}$ in a stepwise manner, and the proposed converter also can balance the bipolar output voltages under a load sudden decrease. 


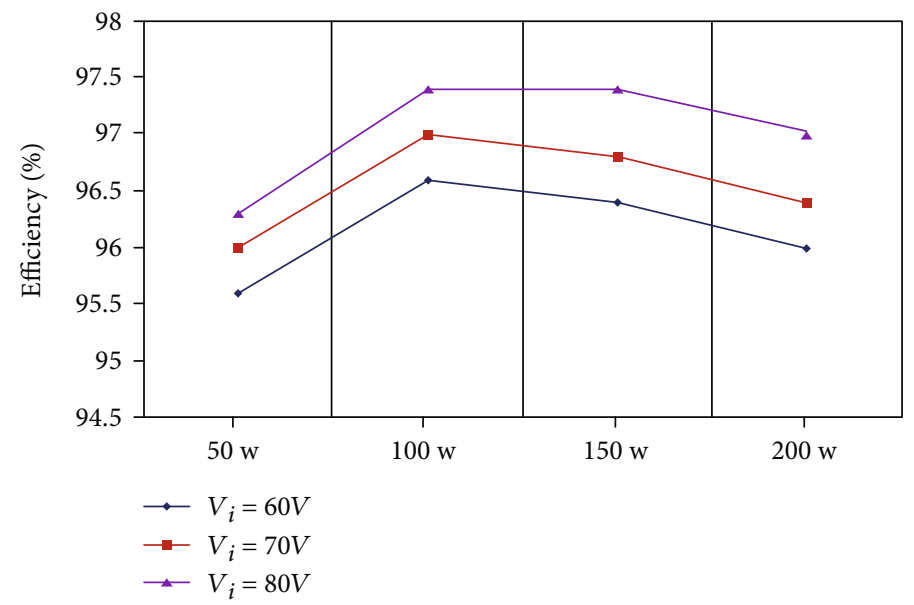

Figure 14: Efficiency curves.

TABLE 3: Loss distribution.

\begin{tabular}{lcc}
\hline Components & Losses $(\mathrm{W})$ & Percentage \\
\hline Switches & $3.325 \mathrm{~W}$ & $53.8 \%$ \\
Diodes & $1.533 \mathrm{~W}$ & $24.8 \%$ \\
Inductors & $1.112 \mathrm{~W}$ & $18 \%$ \\
Capacitors & $0.22 \mathrm{~W}$ & $3.4 \%$ \\
\hline
\end{tabular}

5.2. Efficiency and Power Loss. The designed prototype's efficiency is probed at various input voltage and power levels by experimental measurement. The efficiency plot for various input voltage and power levels is shown in Figure 14. It can be seen that the proposed converter shows a better efficiency performance when $P_{\mathrm{o}}=100 \mathrm{~W}$ and the efficiency exceeds $97.4 \%$ when $V_{\mathrm{i}}=80 \mathrm{~V}$.

The experimental conditions are shown in Table 2. According to Table 2, the detailed loss analysis is as follows:

(1) The losses of the switches $\left(S_{1}\right.$ and $\left.S_{2}\right)$ result from switching and conduction, and they can be estimated as follows:

$$
P_{\mathrm{S}}=2\left[I_{\mathrm{s}(\mathrm{rms})}{ }^{2} R_{\mathrm{DS}(\mathrm{on})}+\frac{1}{2} f_{\mathrm{s}} V_{\mathrm{s}} I_{\mathrm{s}}\left(t_{\mathrm{on}}+t_{\mathrm{off}}\right)\right]=3.325 \mathrm{~W} \text {, }
$$

where $I_{\mathrm{s}(\mathrm{rms})}$ is the RMS current of the switches and $R_{\mathrm{DS} \text { (on) }}$ is the on-state resistance of the switches; $f_{s}$ is switching frequency; $t_{\text {on }}$ and $t_{\text {off }}$ are turn-on time and turn-off time, respectively; $V_{\mathrm{s}}$ is the voltage stress of the switches, and $I_{\mathrm{s}}$ is the current of the switches during switching time

(2) The diode losses are given by

$$
P_{\mathrm{D}}=2\left[I_{\mathrm{D}(\mathrm{avg})} v_{\mathrm{F}}\right]=1.533 \mathrm{~W},
$$

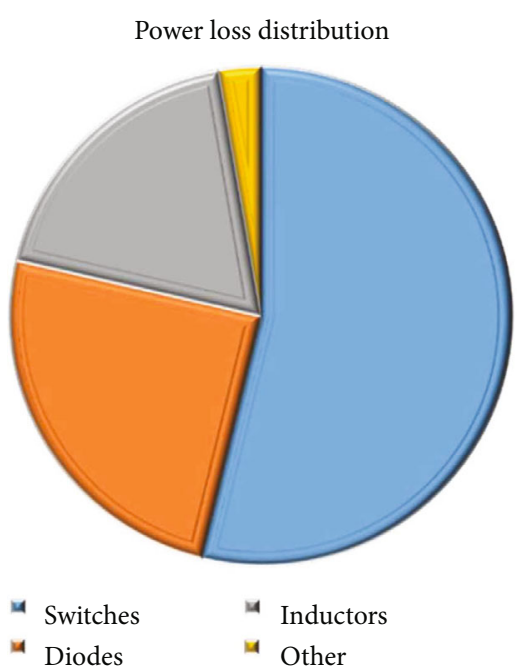

Figure 15: Power loss distribution.

where $I_{\mathrm{D}(\mathrm{rms})}$ is the average current of the diodes and $v_{\mathrm{F}}$ is the diode forward voltage

(3) The inductor losses are given by

$$
P_{\mathrm{L}}=2\left[r_{\mathrm{L}} I_{\mathrm{L}(\mathrm{rms})}^{2}+\left(a B_{\mathrm{pk}}^{b} f_{\mathrm{s}}^{c}\right) A_{e} l_{e}\right]=1.112 \mathrm{~W},
$$

where $I_{\mathrm{L}(\mathrm{rms})}$ is the RMS current of the inductor; $r_{\mathrm{L}}$ is copper resistance; $B_{p \mathrm{k}}$ is the AC magnetic flux density for the magnetic device core; $a, b$, and $c$ are constants determined from the curve fitting of the core; $l_{e}$ is the core medium path length; and $A_{e}$ is the transversal core area

(4) The capacitor losses can be given by

$$
P_{\mathrm{C}}=2\left[I_{\mathrm{C}(\mathrm{rms})}{ }^{2} \mathrm{ESR}\right]=0.22 \mathrm{~W}
$$


where $I_{\mathrm{C}(\mathrm{rms})}$ is the RMS current of the capacitor and ESR is the resistor of capacitors.

So, the loss distribution of the proposed converter for working condition of $P_{\mathrm{o}}=200 \mathrm{~W}, f_{\mathrm{s}}=50 \mathrm{kHz}, V_{\mathrm{i}}=60 \mathrm{~V}$, and $V_{\mathrm{o}}=240 \mathrm{~V}$ is shown in Table 3 and Figure 15 .

\section{Conclusions}

In this paper, a novel bipolar output active-switchedinductor converter was proposed for bipolar DC microgrid. The proposed converter was analyzed from CCM operation analysis, DCM operation analysis, voltage conversion, efficiency analysis considering nonideality, voltage and current stress of power devices, input and output ripple analysis, and design consideration. Finally, the correctness of the theoretical analysis was verified by the results of the simulation and experiment.

The proposed converter has the advantages of high voltage gain and wide duty range, and the operation principle is also simple. The voltage and current stress of power device is relatively low due to the active-switched-inductor network. The proposed converter can output bipolar voltage; the bipolar output voltage is between positive line $(\mathrm{P})$, negative line $(\mathrm{N})$, and common ground $(\mathrm{O})$, which can offer three voltage classes $(\mathrm{Vdc},+0.5 \mathrm{Vdc}$ and $-0.5 \mathrm{Vdc})$. Also, due to the symmetry of the structure, the proposed converter can achieve voltage balance of bipolar output with easy control. The highest efficiency of the proposed converter is about $97.4 \%$.

\section{Data Availability}

The raw data used for this proposed work have been cited in the manuscript. Moreover, the derived data supporting the findings of this study have been graphically depicted and are available with the corresponding author on request.

\section{Conflicts of Interest}

The authors declare that there is no conflict of interest regarding the publication of this paper.

\section{Acknowledgments}

This work was supported in part by S\&T Program of Hebei (20314501D and 19214501D) and Hebei Bureau of Foreign Experts (2019YX005A).

\section{References}

[1] N. Hatziargyriou, "Microgrids [guest editorial]," IEEE Power and Energy Magazine, vol. 6, no. 3, pp. 26-29, 2008.

[2] N. Hatziargyriou, "The microgrids concept," in Microgrids: Architectures and Control, pp. 1-24, Chichester, United Kingdom, 2013.

[3] Y. Tang, D. Fu, T. Wang, and Z. Xu, "Hybrid switchedinductor converters for high step-up conversion," IEEE Transactions on Industrial Electronics, vol. 62, no. 3, pp. 1480-1490, 2015.
[4] S. Anand, B. G. Fernandes, and J. Guerrero, "Distributed control to ensure proportional load sharing and improve voltage regulation in low-voltage DC microgrids," IEEE Transactions on Power Electronics, vol. 28, no. 4, pp. 1900-1913, 2013.

[5] J. M. Guerrero, J. C. Vasquez, J. Matas, L. G. de Vicuna, and M. Castilla, "Hierarchical control of droop-controlled AC and DC microgrids-a general approach toward standardization," IEEE Transactions on Industrial Electronics, vol. 58, no. 1, pp. 158-172, 2011.

[6] J. Lago and M. L. Heldwein, "Operation and control-oriented modeling of a power converter for current balancing and stability improvement of DC active distribution networks," IEEE Transactions on Power Electronics, vol. 26, no. 3, pp. 877-885, 2011.

[7] Y. Tang, D. Fu, J. Kan, and T. Wang, "Dual switches DC/DC converter with three-winding-coupled inductor and charge pump," IEEE Transactions on Power Electronics, vol. 31, no. 1, pp. 461-469, 2016.

[8] S. Singh, M. Singh, and S. C. Kaushik, "Optimal power scheduling of renewable energy systems in microgrids using distributed energy storage system," IET Renewable Power Generation, vol. 10, no. 9, pp. 1328-1339, 2016.

[9] F. Gao and D. Rogers, "Duty-cycle plus phase-shift control for a dual active half bridge based bipolar DC microgrid," in 2018 IEEE Applied Power Electronics Conference and Exposition (APEC), pp. 1479-1485, San Antonio, TX, 2018.

[10] H. Kakigano, Y. Miura, and T. Ise, "Low-voltage bipolar-type DC microgrid for super high quality distribution," IEEE Transactions on Power Electronics, vol. 25, no. 12, pp. 30663075, 2010.

[11] T. Dragičević, X. Lu, J. C. Vasquez, and J. M. Guerrero, "DC microgrids-part II: a review of power architectures, applications, and standardization issues," IEEE Transactions on Power Electronics, vol. 31, no. 5, pp. 3528-3549, 2016.

[12] Z. Zhang, D. Shi, C. Jin et al., "Droop control of a bipolar dc microgrid for load sharing and voltage balancing," in 2017 IEEE 3rd International Future Energy Electronics Conference and ECCE Asia (IFEEC 2017- ECCE Asia), pp. 795-799, Kaohsiung, 2017.

[13] Y. Tang, D. Fu, T. Wang, and Z. Xu, "Analysis of activenetwork converter with coupled inductors," IEEE Transactions on Power Electronics, vol. 30, no. 9, pp. 4874-4882, 2015.

[14] J. Lee, Y. Cho, H. Kim, J. Cho, and J. Kim, "A study on the bipolar DC-DC converter of SST for LVDC distribution," in 2019 10th International Conference on Power Electronics and ECCE Asia (ICPE 2019- ECCE Asia), pp. 2388-2394, Busan, Korea (South), 2019.

[15] S. P. Litrán, E. Durán, M. B. Ferrera, J. Semião, and R. S. Barroso, "A zeta-CSC converter combination for single-input and bipolar output," in IECON 2019-45th Annual Conference of the IEEE Industrial Electronics Society, pp. 5721-5726, Lisbon, Portugal, 2019.

[16] Y. Gu, W. Li, and X. He, "Analysis and control of bipolar LVDC grid with DC symmetrical component method," IEEE Transactions on Power Systems, vol. 31, no. 1, pp. 685-694, 2016.

[17] P. Shamsi and B. Fahimi, "Stability assessment of a DC distribution network in a hybrid micro-grid application," IEEE Transactions on Smart Grid, vol. 5, no. 5, pp. 2527-2534, 2014.

[18] F. Wang, Z. Lei, X. Xinwei, and X. Shu, “Topology deduction and analysis of voltage balancers for DC microgrid," IEEE 
Journal of Emerging and Selected Topics in Power Electronics, vol. 5, no. 2, pp. 672-680, 2017.

[19] P. Zumel, L. Ortega, A. Lazaro et al., "Modular dual-active bridge converter architecture," IEEE Transactions on Industry Applications, vol. 52, no. 3, pp. 2444-2455, 2016.

[20] X. Zhang, C. Gong, and Z. Yao, "Three-level dc converter for balancing dc 800-V voltage," IEEE Transactions on Power Electronics, vol. 30, no. 7, pp. 3499-3507, 2015.

[21] H. Kakigano, Y. Miura, T. Ise, and R. Uchida, "DC voltage control of the DC micro-grid for super high quality distribution," in 2007 Power Conversion Conference-Nagoya, pp. 518-525, Nagoya, Japan, 2007.

[22] Y. Tang, H. Tong, J. Kan, Y. Zhang, and K. Xu, "Symmetric dual-switch converter," IEEE Transactions on Power Electronics, vol. 35, no. 11, pp. 11955-11964, 2020.

[23] J. Lago, J. Moia, and M. L. Heldwein, "Evaluation of power converters to implement bipolar DC active distribution networks-DC-DC converters," in 2011 IEEE Energy Conversion Congress and Exposition, pp. 985-990, Phoenix, AZ, USA, 2011.

[24] X. Zhang and C. Gong, "Dual-buck half-bridge voltage balancer," IEEE Transactions on Industrial Electronics, vol. 60, no. 8, pp. 3157-3164, 2013.

[25] L. Tan, B. Wu, V. Yaramasu, S. Rivera, and X. Guo, "Effective voltage balance control for bipolar-DC-bus-fed EV charging station with three-level DC-DC fast charger," IEEE Transactions on Industrial Electronics, vol. 63, no. 7, pp. 4031-4041, 2016.

[26] C. Xia, X. Gu, T. Shi, and Y. Yan, "Neutral-point potential balancing of three-level inverters in direct-driven wind energy conversion system," IEEE Transactions on Energy Conversion, vol. 26, no. 1, pp. 18-29, 2011.

[27] Y. Tang, T. Wang, and D. Fu, "Multicell switched-inductor/ switched-capacitor combined active-network converters," IEEE Transactions on Power Electronics, vol. 30, no. 4, pp. 2063-2072, 2015.

[28] Q. Tian, G. Zhou, M. Leng, G. Xu, and X. Fan, “A non-isolated symmetric bipolar output four-port converter interfacing PVbattery system," IEEE Transactions on Power Electronics, vol. 35, no. 11, pp. 11731-11744, 2020.

[29] M. Szarek, A. Penczek, R. Stala, S. Piróg, and A. Mondzik, "NPC three level inverter with dual DC bus for independent distributed generators. Neutral-point voltage balancing under the input power imbalance," in 2017 19th European Conference on Power Electronics and Applications (EPE'17 ECCE Europe), pp. 1-10, Poland, 2017.

[30] U. Choi, F. Blaabjerg, and K. Lee, "Independent control strategy of two DC-link voltages for separate MPPTs in transformerless photovoltaic systems using neutral-point-clamped inverters," in 2014 IEEE Applied Power Electronics Conference and Exposition - APEC, pp. 1718-1724, USA, 2014.

[31] D. Banerjee, A. Saxena, and M. S. Hashmi, "A novel concept of virtual impedance for high frequency tri-band impedance matching networks," IEEE Transactions on Circuits and Systems II: Express Briefs, vol. 65, no. 9, pp. 1184-1188, 2018.

[32] T. V. Hoang, T. D. Nguyen, and H. Lee, "Adaptive virtual impedance control scheme to eliminate reactive power sharing errors in islanded microgrid," in 2016 IEEE International Conference on Sustainable Energy Technologies (ICSET), pp. 224229, Vietnam, 2016. 